\title{
Using the ALADYM simulation model for exploring the effects of management scenarios on fish population metrics
}

\author{
Maria Teresa Spedicato ${ }^{1, a}$, Jean-Charles Poulard ${ }^{2}$, Chrissi-Yianna Politou ${ }^{3}$, Krzysztof Radtke $^{4}$, \\ Giuseppe Lembo ${ }^{1}$ and Pierre Petitgas ${ }^{2}$ \\ ${ }^{1}$ COISPA Tecnologia \& Ricerca, Via dei trulli 18-20, 70126 Bari, Italy \\ 2 IFREMER, Dept. Ecologie \& Modèles Halieutiques, EMH, BP 21105, 44311 Nantes, France \\ 3 Hellenic Centre for Marine Research, Agios Kosmas, 16777 Helliniko, Greece \\ ${ }^{4}$ Sea Fisheries Institute, Kołłtaja 1, 81-332 Gdynia, Poland
}

Received 16 February 2009; Accepted 30 March 2010

\begin{abstract}
Simulation of fisheries systems is a widely used approach that integrates monitoring and assessment tools. We applied the ALADYM (age-length based dynamic model) simulation model to three different studies aimed at investigating correlations between pressure and population metrics, exploring the viability of different mortality levels in long-term scenarios and predicting the effects of combined management measures. Uncertainty was incorporated into the simulations following the Monte Carlo paradigm. Three stocks were used for these exercises: red mullet in the central-southern Tyrrhenian Sea and European hake in both the Bay of Biscay and the Aegean Sea. The analysis of the relationships between total mortality and indicators highlighted significant pairwise negative correlations for red mullet. These signals of decline were supported by the spawning potential ratio indicator (mean exploited to mean unexploited spawning-stock biomass $E S S B / U S S B$ ), which was low compared to target levels. It only remained within safe bounds ( $>0.2$; probability: 0.90-0.95) at total mortality levels lower than 1.6. The simulation results for European hake in the Bay of Biscay showed that a sustainable exploitation rate might range from 0.87 to 1.04 . The benefits of combined management measures were demonstrated for European hake in the Aegean Sea, and with a further dataset on the Eastern cod stock in the Baltic Sea.
\end{abstract}

Key words: Simulation model / Model-based indicators / Fishery management / Reference points / Mullus barbatus / Merluccius merluccius / Mediterranean Sea / Atlantic Ocean

\section{Introduction}

Simulation of fisheries systems is a widely used approach that integrates monitoring and assessment tools (e.g. National Research Council, NRC 1998). It is also potentially useful for several other objectives, such as to check the validity of assessment and management methods and to see whether unrealistic values are being considered in designing stock dynamics (e.g. Cotter et al. 2009a). Furthermore, simulations are used to describe the dynamics of populations, to verify their current status and to make projections about stocks in the future, under defined conditions (e.g. Cooke 1999; Punt 2003). In an evaluation framework based on indicators, simulations obtained by modelling can be used to assess performance of the indicators (Rochet and Trenkel 2009) in relation to different fishing scenarios, and consequently to underpin the diverse impact levels of selected metrics.

A suite of applications can thus be assisted by simulations for testing a hypothesis, estimating reference points,

\footnotetext{
a Corresponding author: spedicato@coispa.it
}

evaluating management options, designing harvest control rules and testing indicator performance in response to different fishing pressure levels.

Modelling of management scenarios is usually based on simulations that intend to provide stakeholders with indicative profiles of the viability of exploitation patterns on target stocks, thus helping the fisheries management system to fulfil the priority objective of ensuring the wise use of renewable marine resources over the long-term. However, simulation results alone are not sufficient and need to be complemented with all available knowledge to effectively support decisionmaking (Rochet and Rice 2009). Specification of uncertainty in the planning of different scenarios and in the key parameters would allow simulation models to better grasp reality and encompass a wide range of possible natural fluctuations and stock responses to management actions.

Taking into account uncertainty is a complex issue, given the nature of each fishery and our incomplete understanding of population dynamics, as several types of unknown element impact fishery assessments, including parameter, model and 
process uncertainty (e.g. Hilborn and Mangel 1997; Haddon 2001; Wang et al. 2009). In addition, experience has demonstrated that implementation uncertainty is very likely to greatly exceed any slight quantitative differences between simulation results (Rochet and Rice 2009).

Incorporating uncertainty in simulation models may require the use of different statistical techniques such as maximum likelihood and Bayesian methods, bootstrapping and Monte-Carlo modelling.

In this study we applied the ALADYM (age-length based dynamic model) simulation model (Lembo et al. 2009), a tool that does not requiring fishery-dependent data, and that operates on a monthly time scale mimicking the population at sea by the generation of numbers at age from a stock recruitment relationship or, alternatively, from a recruitment vector. This model is particularly useful to explore changes resulting from management measures, such as variations in size at first capture or fishing activity in situations such as the Mediterranean, where fish populations are generally exploited from a young age (e.g. Caddy 2006). Simulated management options are mainly based on technical measures, termed "passive management" by Caddy (2006), which include fishing gear selectivity and closed seasons, that may be applied alone or in combinations.

To represent the uncertainty inherent in the stock dynamics, ALADYM uses different stock-recruitment relationships and natural mortality options, while the implementation of a Monte Carlo approach allows it to account for uncertainty in knowledge about recruitment, growth and maturity parameter values. As Monte Carlo techniques require resampling from statistical distributions, key parameters are represented by their probability density functions ( $p d f s$ ) instead of by their average values. The $p d f s$ (log-normal, normal, gamma and uniform) can be assigned independently to each parameter. The stochastic effects thus incorporated into some of the key life-history traits simulate the uncertainty in the input data and parameter relationships, accounting for measurement, process and estimation errors. This allows assessment of the robustness of the results and provides warning information about uncertainties.

Further details regarding model specifications, basic assumptions, equations, advantages and limitations can be found in Lembo et al. (2009).

In the present study we conducted three types of ALADYM application. To start with, the model was used for investigating correlations between pressure (total mortality) and population metrics (e.g. life history traits, biomass, yield and biological production). In addition, the combined influence of pressure and trends of population traits (for example, recruitment) on model-based indicators was also investigated, trying to disentangle possible environmentally driven effects from pressure related consequences. Furthermore, we explored the results of different long-term pressure scenarios on selected population metrics derived from simulations (e.g. the ratio of the exploited to the unexploited spawning-stock biomass $E S S B / U S S B$ ). The aim was to estimate indicative reference points for sustainable fishing pressures. For this test, the stock of red mullet (Mullus barbatus) in the central-southern Tyrrhenian Sea was used as a case study.
In the second application, the sensitivity and pertinence of different population metrics for indicating changes in population dynamics was evaluated through simulation. ALADYM was employed for testing whether estimated levels of total mortality $(Z)$ were viable in the long-term (20-40 years). For this exercise, the stock of European hake (Merluccius merluccius) in the Bay of Biscay was used.

The third application made a classical use of fisheries simulation models, estimating the effects of different management scenarios on the population dynamics of European hake in the Aegean Sea. Thus, time series of metrics characterising fish population attributes were simulated under different management strategies (effort limitation, size at first capture, etc.).

Different metrics were evaluated from the simulation results: mean length of exploited population (i.e. with fishing mortality $F>0$ ), of exploited spawning population and of unexploited population (i.e. with $F=0$ ), biomass, spawningstock biomass, yield, mean length of catches and biological production (i.e. fishing yields and natural losses). In addition, the following indicators, expressed as ratios, were also computed: $E S S B / U S S B, E S S B / E B$ (exploited spawning biomass to exploited biomass) and ESSB/Yield.

\section{Material and methods}

\subsection{Case studies, model assumptions and specifications}

The model inputs for red mullet in the central-southern Tyrrhenian Sea were mainly from trawl-survey data, except for size at first capture $\left(L_{50}\right)$ and selection range (SR), which were from selectivity experiments conducted in the area, using a commercial trawl net. Considering the early stage of exploitation for red mullet in the area, natural mortality was set to vary with age/length, according to the Chen and Watanabe model (1989), as implemented in ALADYM. A Ricker-type stock-recruitment relationship was assumed for the red mullet, according to the knowledge on this species in a contiguous area (Levi et al. 2003).

The mode inputs model for European hake in the Bay of Biscay and Aegean Sea were obtained from trawl-surveys and, for some parameters, from the literature. To initialise the model, recruitment was assumed to be log-normally distributed and randomly varying around trawl survey estimates for European hake in both the Bay of Biscay and Aegean sea, without any pre-defined stock-recruitment relationship. Natural mortality was set as constant for these two stocks, following the Beverton and Holt invariant paradigm (Jensen 1966).

Growth $\left(L_{\infty} ; \mathrm{K}\right)$ and maturity (length at first maturity $L_{m 50}$ and maturity range MR $L_{\mathrm{m} 75}-L_{\mathrm{m} 25}$ ) parameters were set with relative $p d f s$ (normal and uniform, respectively). A uniformly distributed multiplier was introduced for recruitment to add a source of stochasticity to the offspring values, in order to model small perturbations in the environment. Following the Monte Carlo paradigm, random samples for recruitment, individual growth and size at maturity were drawn from the selected $p d f s$ to start the population distribution. This population was then allowed to evolve over time, performing 1000 runs for each simulation. The outputs from the runs were used to 
calculate descriptive statistical parameters (mean and standard deviation), useful to measure the range of the results. In addition, the projection outputs of interest were also summarised as frequency distributions or probability profiles.

Model settings for the three selected stocks are summarised (Tables 1a-b, 1a: deterministic parameters and data, $1 \mathrm{~b}$ : parameters varying according to the associated $p d f s$.

\subsection{Simulation objectives}

The simulation studies had three main objectives (see Table 2 for a summary on the simulation framework). The first objective was twofold:

- To explore correlations between pressure and population metrics based on the model, while also trying to understand effects on these metrics of other changes apparently driven by the environment, such as recruitment trends;

- To search for reference points of selected metrics.

Thus, ALADYM was used to investigate the relationships between historic levels of $Z$, recruitment changes and simulated population indicators.

For the red mullet, the estimated total mortality rates in the years 1994-2003 were used for the first 10 years of the simulation (Table 3, estimates from MEDITS trawl surveys, according to the method outlined in Cotter et al. 2009b). This time series of $Z$ values was then extended to the following 10 years (total $=20$ years).

All simulation results were analysed by plotting pairwise relationships of population indicators and total mortality $Z$. These relationships were analysed under the hypothesis of different time lags (year 1-20 vs. year 1-20; years 1-19 vs. year 2-20; etc.), to establish when the highest correlation was found.

Following a similar approach, the exercise was extended to the simulation of effects of factors other than fishing pressure on the population (Table 2). Thus, $Z$ was set as changing (Table 3), however, an increasing trend was introduced in recruitment $(+5 \%$ each year).

In addition, 13 independent stochastic simulations were conducted to search for reference points of selected metrics (Table 2). A pseudo-equilibrium approach was used in these simulations, as only recruitment varied, while pressure and other parameters were kept constant over time (20 years). Total mortality $Z$ ranged from 1.2 to 2.4 in $Z$ steps $=0.1$, and 1000 runs were performed for each simulation.

The second objective of the simulation studies was to explore the impact of a range of total mortality rates, aimed at the selection of reference values for $Z$, in terms of a maximum level that would ensure the viability of the stock of European hake in the Bay of Biscay in the long-term (Table 2). Thus, three scenarios were created, in which total mortality changed between scenarios and over time. The total mortality was set using a 1.04 constant value for the period 1987-2001, and a higher value of 1.8 from 2002 to 2004 for all the three scenarios; then, it was changed as follows (Table 3):

- In the " $Z$ mean" scenario, total mortality was decreased gradually from 1.8 in the period 2002-2004 to the initial level of 1.04 by the end of the simulation (year 2026);
- In the " $Z$ low" scenario, total mortality was reduced to 0.78 from 2005 to the end of the simulation;

- In the " $Z$ high" scenario, total mortality was maintained at the high value of 1.8 in 2002-2004 to the end of the simulation (2026).

The third objective was to test composite management scenarios building on the biological complexity formulated in the population model. For this purpose, European hake in the Aegean Sea was used (Table 2). Population modelling was based on the total mortality indices $(Z \sim 0.89)$ estimated for the period 1994-2003. Slightly lower values $(Z \sim 0.82)$ were then projected forward from 2004 to 2013 . For the period 2014-2033, total mortality was decreased to 0.78 to simulate the long-term effects of pressure reduction (Table 3 ). This was combined with a further decrease in fishing mortality obtained by varying the size at first capture, which was increased $\left(L_{50}=108 \mathrm{~mm}\right)$ from year 8 onward (2001) as a result of a new cod-end mesh opening enforcement $(40 \mathrm{~mm})$. Over the time of the simulation, summer fishing activity was kept lower $(\sim 0.44)$ than for the rest of the year to account for the seasonal fishing ban of trawlers in June-September. An alternative sub-model for selectivity was used (product of ogives sub-model selection parameter $D_{50 \%}$; Lembo et al. 2009) to simulate a harvesting pattern accounting for vulnerability/accessibility of the fish to the fishing gear. This was based on the knowledge about the fishing grounds targeted by differently equipped fishing units and the distribution of adult European hake in this area, where this species inhabits the deeper waters (Anonymous 2006).

Population metrics were examined for the generated time series of all the case studies.

\section{Results}

The relationships between fishing pressure factor $(Z)$, population (total and spawning biomass and mean length of exploited population) and removal metrics (yield, biological production and mean length of catches) showed significant pairwise negative correlations (range of regression coefficient: minimum 0.32 for yield; maximum 0.89 for spawning-stock average length), with a 2-year time lag (Fig. 1). The contrast of the pressure levels between the time series (Table 3, red mullet) allowed us to evaluate the sensitivity of an indicator, whereas the delay in the responsiveness might be interpreted by considering a cascade effect between successive cohorts combined with the species growth rate. Total and fishing mortality were only, as expected, positively and highly correlated. The negative correlations between $Z$, yield and biological production were probably the consequence of the high exploitation of red mullet stock. Pressure levels might have been beyond the maximum of the yield curve, thus the mortality increase did not produce additional yield or biological production, but caused a progressive decline in both.

In the scenario simulating a growing trend in recruitment, the negative correlation between spawning-stock biomass and $Z$ was still significant, although weaker (coefficient of the regression 0.41 vs. 0.76 , Fig. 1) compared with the dynamics in which the offspring were regulated by the stock-recruitment relationship. In this exercise, however, the masking effects of 


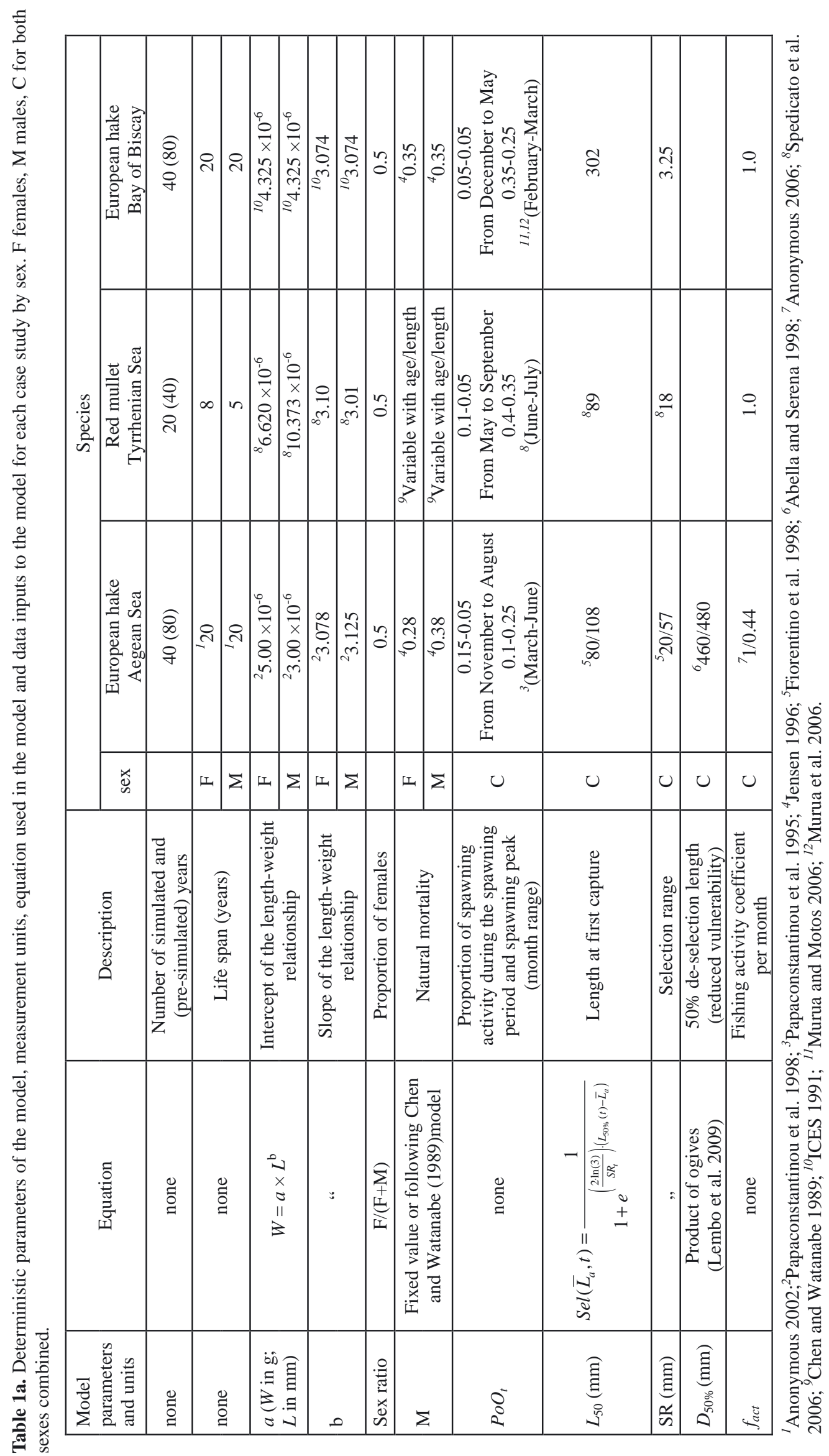




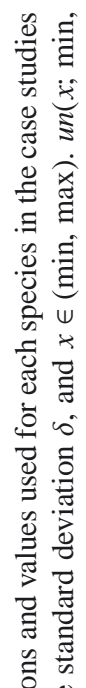

虽

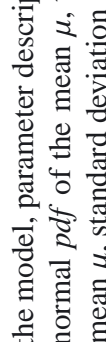

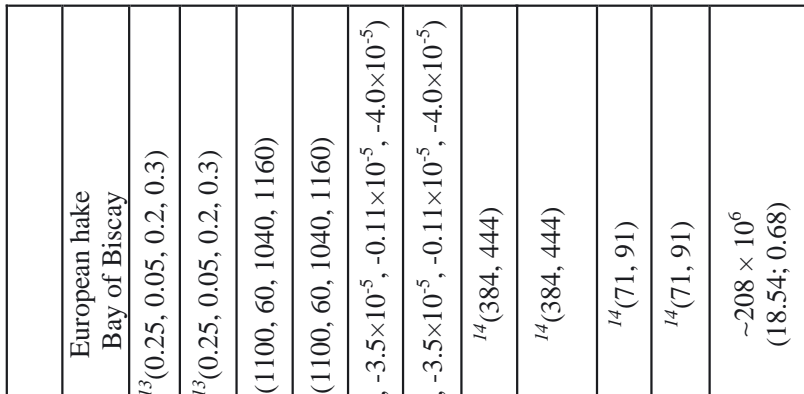

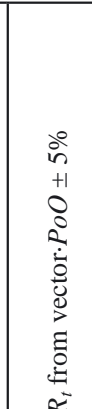

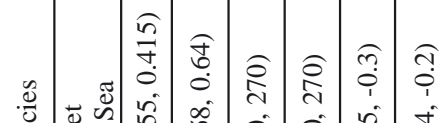

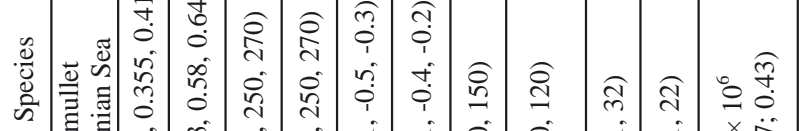

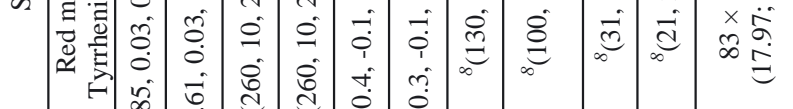

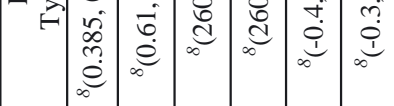

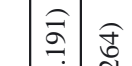

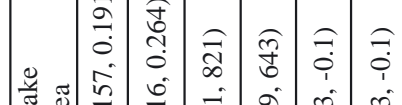

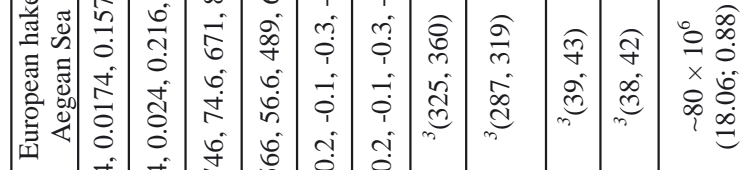

焉焉

:

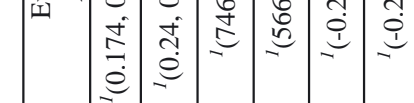

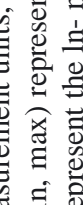

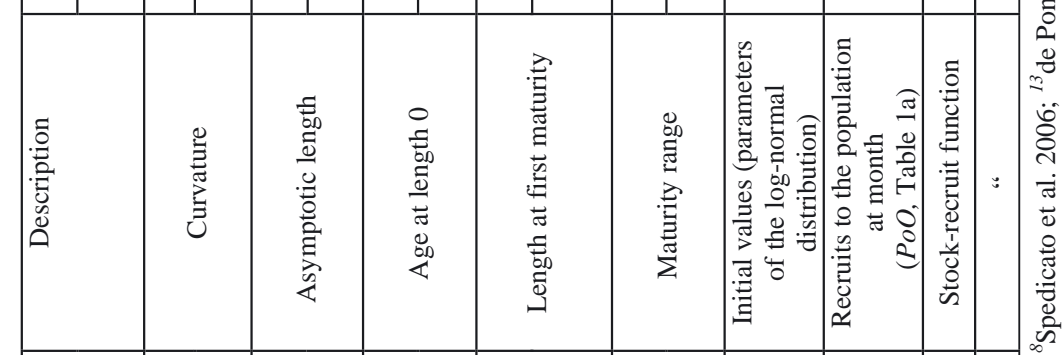

․ㅠㅇ

हैं

马ु

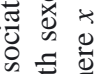

\begin{tabular}{|l|l|l|l|l|l|l|l}
\hline & & & & & & & \\
\hline
\end{tabular}

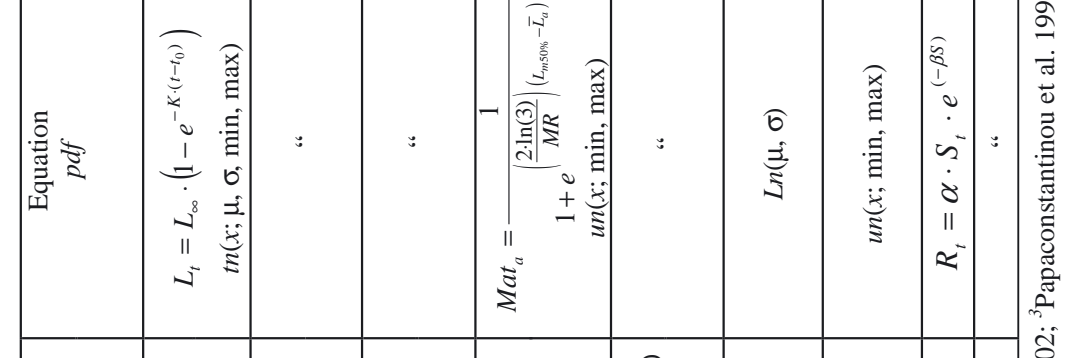

$\stackrel{0}{0}$

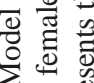

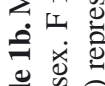

产 尝 


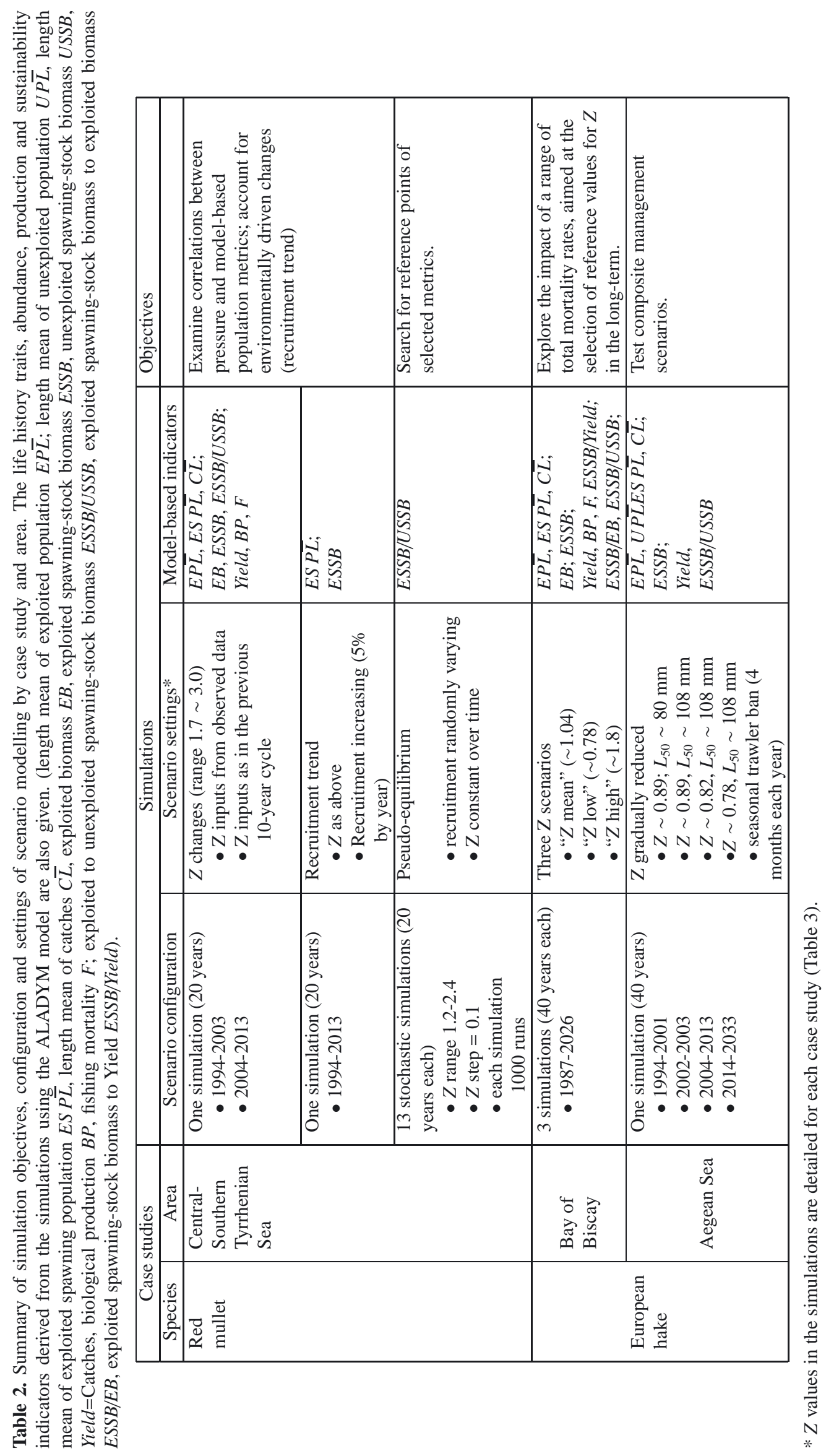


Table 3. Total mortality rates by year used for simulation studies. Red mullet: " $Z$ curr" indicates the current values of total mortality, while " $Z$ unch" indicates that a cycle of total mortality equal to the past decade is repeated. European hake in the Bay of Biscay: Total mortality scenarios from 2005 to 2026; " $Z$ mean"; " $Z$ low"; " $Z$ high" that follow the $Z$ curr setting. European hake in the Aegean Sea: Total mortality values in the current (Zcurr) and in the " $Z$ low" scenarios.

\begin{tabular}{|c|c|c|c|c|c|c|c|c|}
\hline \multicolumn{3}{|c|}{$\begin{array}{c}\text { Red mullet } \\
\text { Tyrrhenian Sea }\end{array}$} & \multicolumn{3}{|c|}{$\begin{array}{c}\text { European hake } \\
\text { Aegean Sea }\end{array}$} & \multicolumn{3}{|c|}{$\begin{array}{l}\text { European hake } \\
\text { Bay of Biscay }\end{array}$} \\
\hline Year & & $Z$ & Year & & $Z$ & Year & Z & \\
\hline 1994 & \multirow{10}{*}{$Z$ curr } & 1.77 & 1994 & \multirow{10}{*}{$Z$ curr } & 0.87 & $1987-2001$ & \multirow{3}{*}{$Z$ curr } & \multirow[t]{2}{*}{1.04} \\
\hline 1995 & & 2.09 & 1995 & & 0.85 & & & \\
\hline 1996 & & 2.44 & 1996 & & 0.97 & 2002-2004 & & 1.84 \\
\hline 1997 & & 2.55 & 1997 & & 0.85 & & \multirow{4}{*}{$Z$ mean } & \multirow{4}{*}{1.04} \\
\hline 1998 & & 2.65 & 1998 & & 0.84 & & & \\
\hline 1999 & & 2.08 & 1999 & & 0.73 & & & \\
\hline 2000 & & 1.71 & 2000 & & \multirow{2}{*}{0.96} & & & \\
\hline 2001 & & 2.73 & 2001 & & & & \multirow{3}{*}{$Z$ high } & \multirow{3}{*}{1.84} \\
\hline 2002 & & 3.01 & 2002 & & 0.98 & $2005-2026$ & & \\
\hline 2003 & & 2.87 & 2003 & & 0.91 & & & \\
\hline \multirow[t]{2}{*}{$2004-2013$} & \multirow{2}{*}{\multicolumn{2}{|c|}{$1.77-2.87$}} & 2004-2013 & \multirow[b]{2}{*}{$Z$ low } & $0.8-0.85$ & & \multirow[b]{2}{*}{$Z$ low } & \multirow[b]{2}{*}{0.78} \\
\hline & & & 2014-2033 & & 0.78 & 2005-2026 & & \\
\hline
\end{tabular}

a)
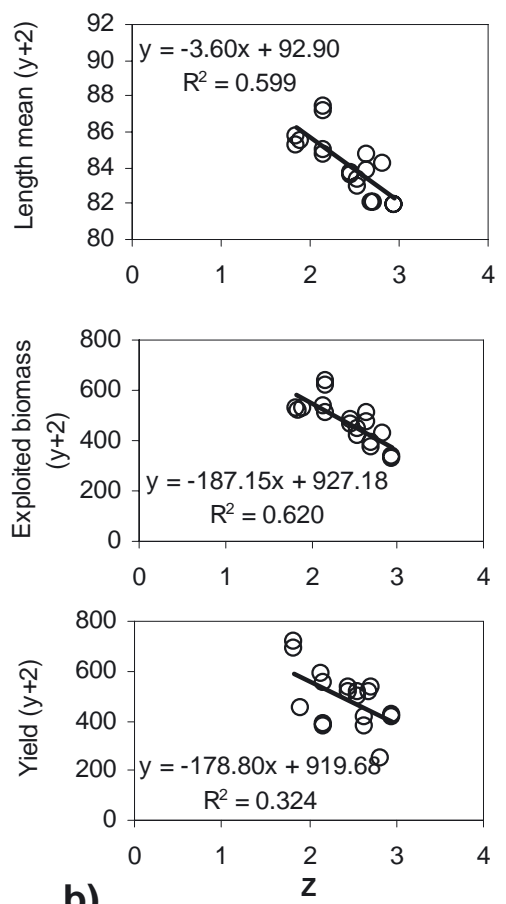

b)

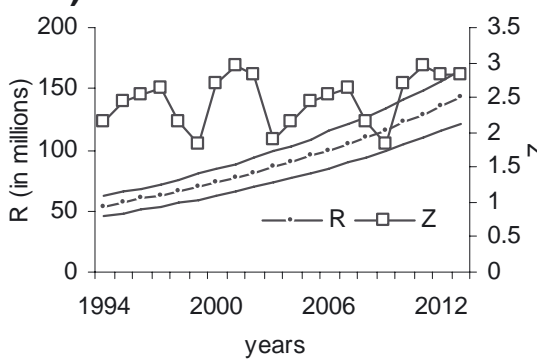

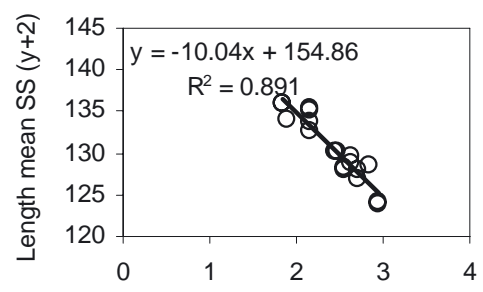
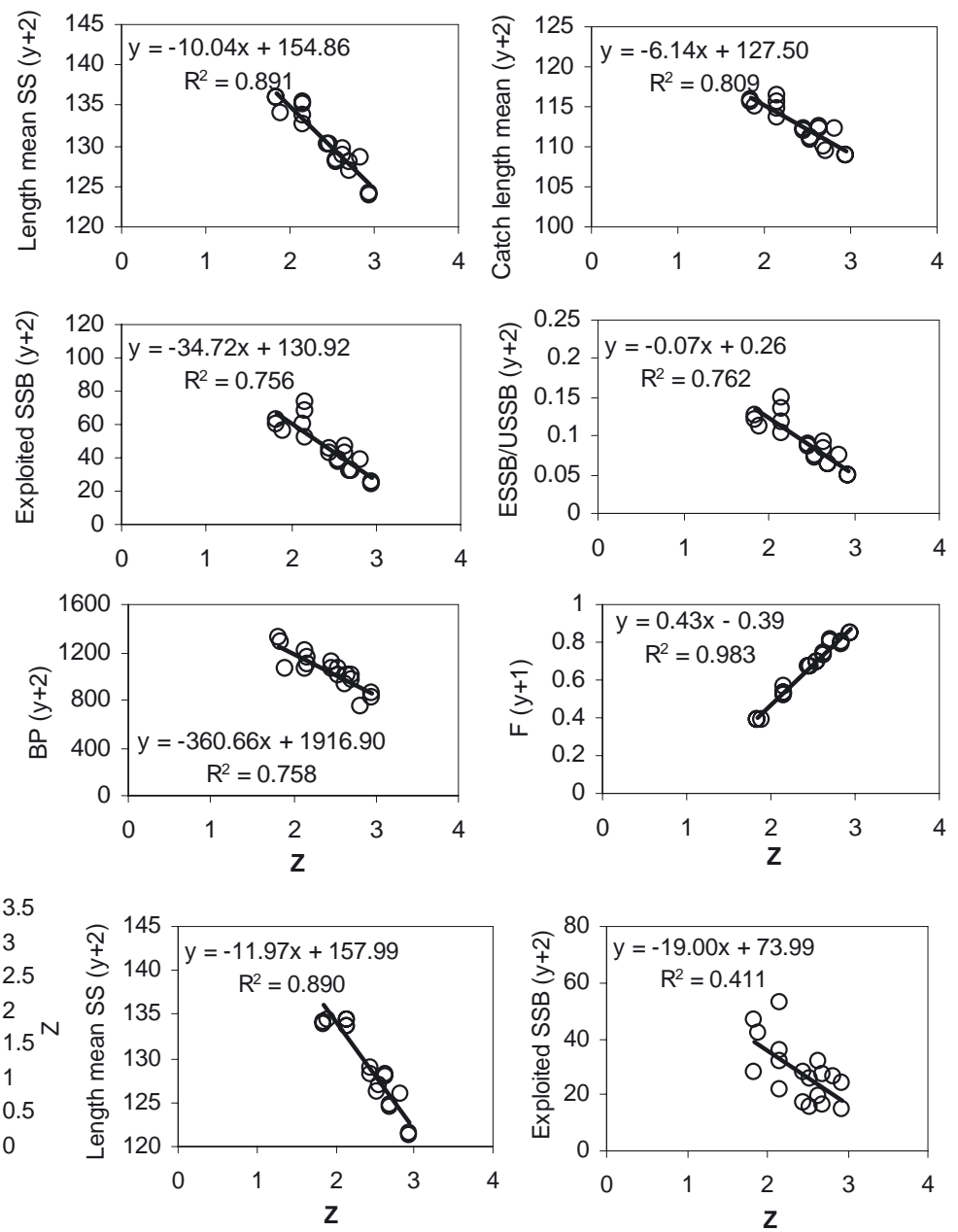

Fig. 1. Red mullet in the Tyrrhenian Sea. Pairwise relationships between fishing pressure factors $(Z)$ and model-based metrics a) without trend; b) when an increasing trend was introduced in the recruitment (left plot). The population was simulated for 20 years using ALADYM with parameters as in Tables 1a-b and Table 3. In each plot, the fitted linear model and the coefficient of determination are indicated. 


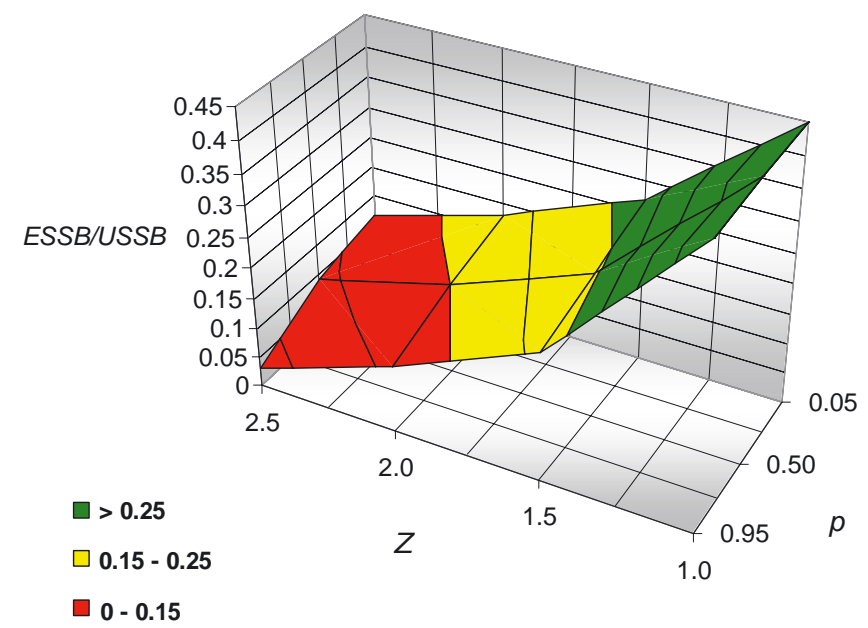

Fig. 2. Red mullet in the Tyrrhenian Sea. Average ratios (over 20 years) of exploited to unexploited spawning-stock biomass $(E S S B / U S S B)$ for scenarios of total mortality $(Z)$ from 1.2 and 2.4 and different probability levels $(p)$. Simulations (1000 runs for each $Z$ scenario) over 20 years. Results are presented according to the trafficlight convention (Caddy 2006).

growing recruitment, driven for example by increased environmental productivity, on high mortality were still distinguishable.

The correlation between the mean length of the spawningstock and $Z$ was comparable (coefficient of the regression 0.89 , Fig. 1) between the two scenarios. Thus, the two signals provided a convergent response.

From these exercises, the sustainability indicator $E S S B / U S S B$ was chosen to estimate reference points associated with a range of plausible $Z$ scenarios (Fig. 2). The results of this analysis are summarised according to the traffic-light convention (Caddy 2006) and expressed in terms of probability, derived from cumulative probability profiles. Safe levels (green colour) of ESSB/USSB occurred, with a 0.95 probability, when total mortality was lower than 1.6 over 20 years. Alert levels (yellow colour; indicator level: $0.16-0.22$ ) were estimated with a 0.95 probability when the $Z$ values ranged from 1.6 to 1.9 , whereas alarm levels (red colour) occurred at scenarios with $Z$ higher than 1.9. Assuming a current average rate of total mortality of around 2 for the red mullet (a high level determined by intense exploitation and fairly fast growth rate), the diagnosis is one of alarm and stock deterioration. This condition is apparent despite the effect of a rather high density-dependent stock-recruitment relationship that, although plausible according to knowledge on the species (Levi et al. 2003), mitigates the consequences of high mortality on the $E S S B / U S S B$ indicator.

In the case study for European hake in the Bay of Biscay, besides the $E S S B / U S S B$ ratio, two other model-based indicators, $E S S B / E B$ and $E S S B / Y i e l d$, were used to select reference values for $Z$ in terms of maximum levels that would ensure stock viability. Of the latter two indicators, the first is more sensitive to changes in recruitment, while the second illustrates the effect of the fishing pressure, making it easier to propose management action that would lead to a more stable catch level.
The " $Z$ high" scenario describes changes that would occur in the European hake population if fishing pressure is projected forward at the same level as occurred from 2001 to 2004. All indicators exhibited decreasing trends, with some improvements in years with very good recruitment (Fig. 3), although this effect was of short duration. All indicators (Table 4) and the $E S S B / E B$ ratios (mean 0.25), or $E S S B / U S S B$ (mean 0.02) were the lowest out of the different scenarios (Fig. 3).

In the " $Z$ mean" scenario, the fishing pressure was projected forward at the level of the period 1987-2001. In this scenario, that can be considered as a continuation of the past, the indicators performed as follows: $E S S B / E B$ mean 0.36; $E S S B / U S S B$ mean 0.09 (Table 4, Fig. 3). The comparison between the true catches, as reported by the official statistics, and those obtained by simulation appear to be close (Fig. 4).

The last scenario, " $Z$ low", resulted in an increase, on average, of all population production indicators and the $E S S B / E B$ and $E S S B / U S S B$ ratios, which reached mean values of 0.41 and 0.17 , respectively. The lowest catch was predicted for 2005, with later catches higher and less variable than for any other scenario. Indeed, the ESSB/Yield ratio reached, an average value of 1.04 that was almost twice the value of the "mean" scenario (0.6) and 5 times the level of the "high" scenario (0.22).

The tests of composite management scenarios, that were performed using European hake in the Aegean Sea, showed the beneficial effects of a decrease in total mortality from 2004 onwards. This process was also facilitated by the increase in mesh size in 2001 and, in general, by the complementary measure of a fishing ban during the summer season (JuneSeptember). Given the life span of the species ( 20 years), the improvement of the stock condition became evident after 2014, with a continuous rising phase for all the population and production indicators (a selection is reported in Fig. 5), due to the cumulative effects along cohorts. After a decrease following the implementation of the new scenarios, yield also showed an improvement, reaching the levels of the previous period. The biomass of spawners seemed to be the indicator most sensitive to pressure reduction for this stock. From 2014 onwards, a new and safer state seems to be reached, as shown by the $E S S B / U S S B$ indicator, which was about 0.07 at the beginning but gradually grew to values of 0.17 when the pressure was reduced (Fig. 6).

\section{Discussion}

The quantitative results of simulations represent a helpful source of information to support decision-making. In this study, simulation results are also considered as knowledge that relies principally upon fishery-independent information (Cotter et al. 2009a).

The analysis of the relationships between total mortality and population metrics derived from the ALADYM model showed significant negative pairwise correlations between pressure factors and population metrics for red mullet in the central-southern Tyrrhenian sea, demonstrating the sensitivity and responsiveness of the indicators. These relationships were still significant when an increasing trend was simulated in the 


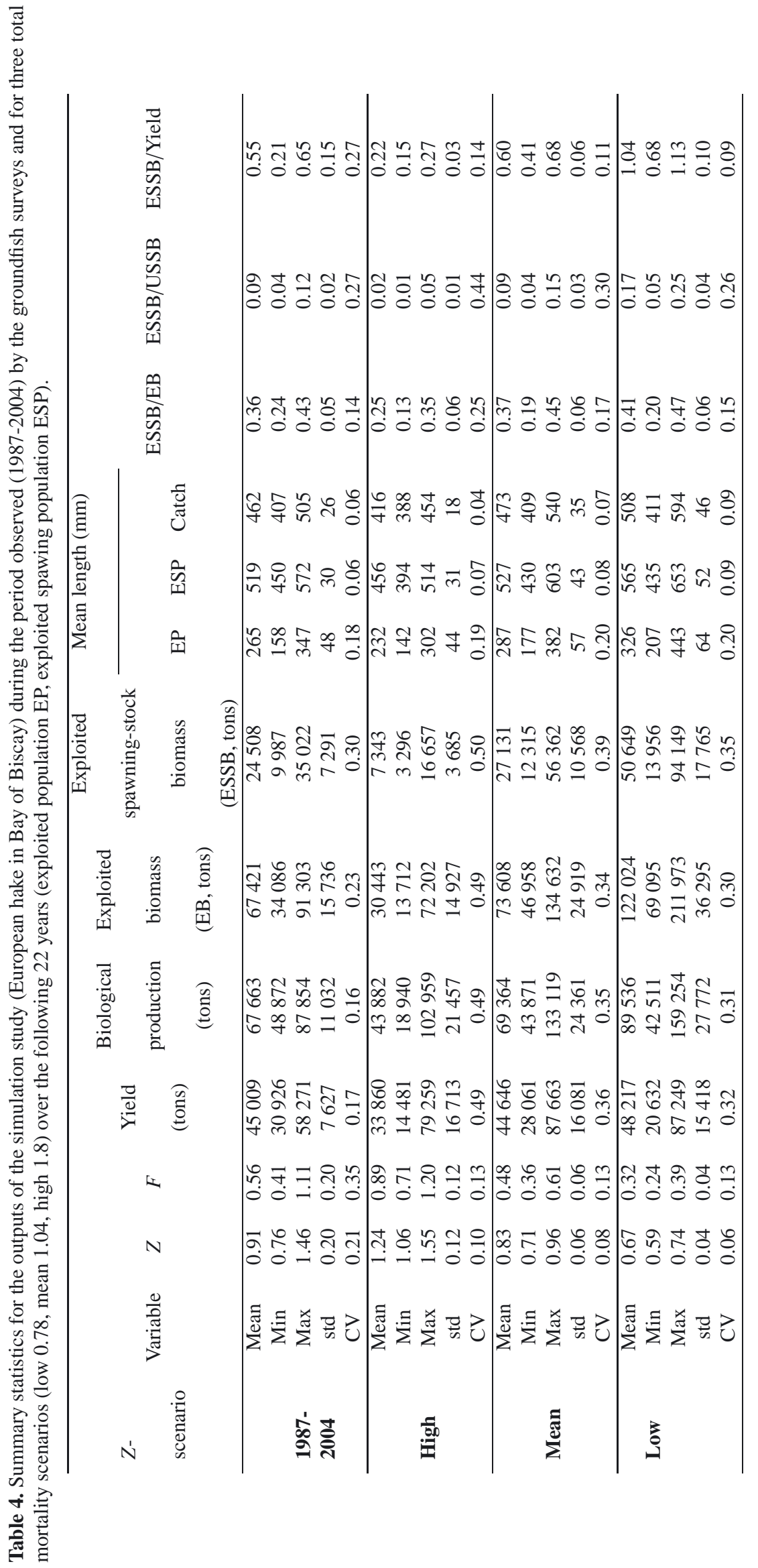



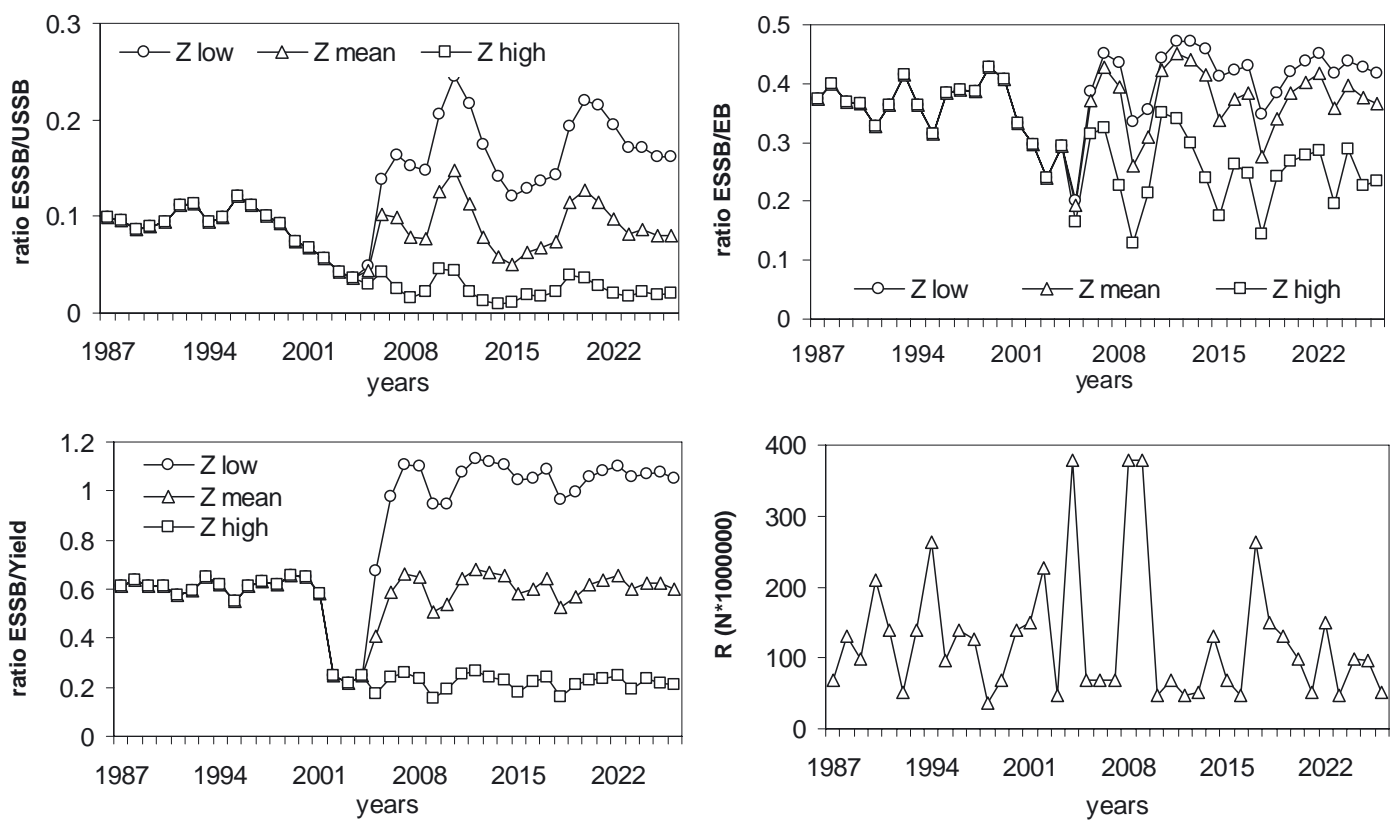

Fig. 3. Scenarios simulated for European hake in the Bay of Biscay. Performance of three selected indicators $(E S S B / U S S B$; $E S S B / E B$; $E S S B / Y i e l d$; where $E S S B$ is the exploited spawning-stock biomass, USSB is the unexploited spawning-stock biomass, $E B$ is the exploited biomass) to assess the viability of three different levels of $Z$. Input recruitment (in millions) is also given.

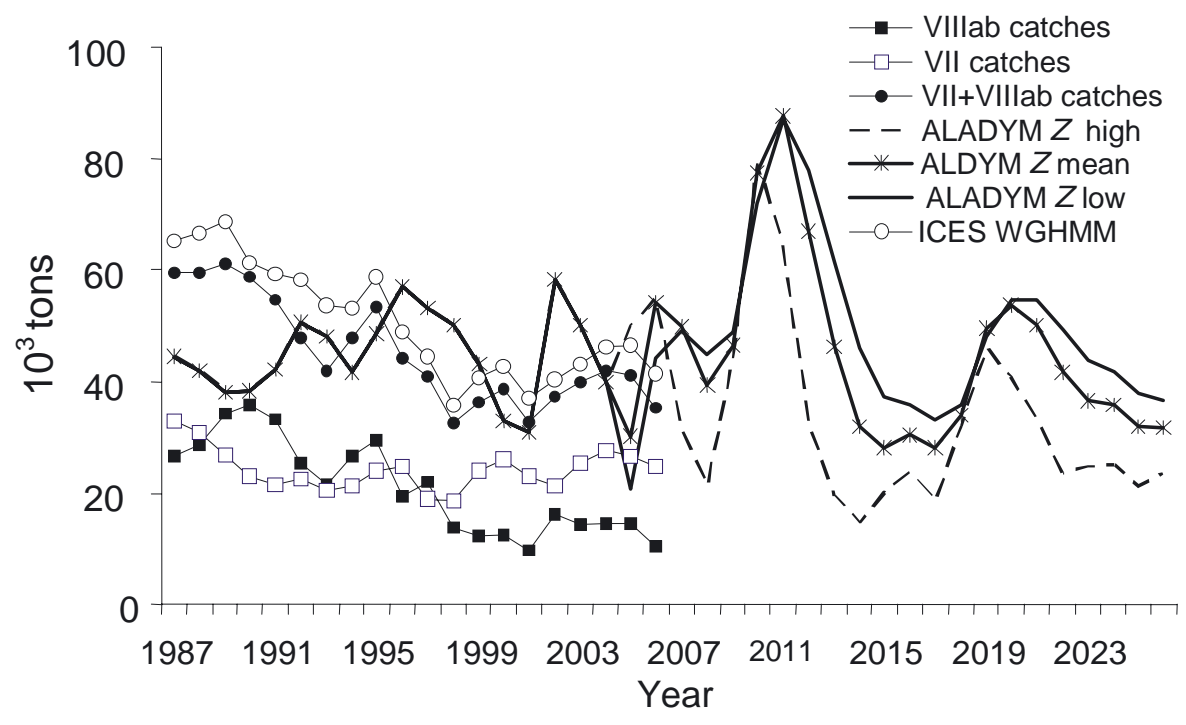

Fig. 4. Simulations of ALADYM model for European hake in the Bay of Biscay: European hake catches used by the ICES Working group GHMM (total northern hake stock, in ICES divisions VII, VIIIab) and ALADYM simulated catches from 2005 to 2026 for three scenarios of $Z$.

recruitment, thus providing evidence of the prevalence of the mortality effects.

The occurrence of significant negative correlations between all indicators and pressure can be interpreted as stock dynamics in a descending phase. This hypothesis is also supported by the level of the ESSB/USSB indicator, which would reach safer ranges (higher than 0.20; Mace and Sissenwine 1993; Mace 1994), with a high level of probability (0.9-0.95), if the total mortality did not exceed values of about 1.6. In this study, we simulated the uncertainty about the knowledge of recruitment, growth and maturity parameter values using the
Monte Carlo approach. However, we could not consider future demographic uncertainty (Maunder et al. 2006), as knowledge on probability distributions, needed to model interactions between demography and possible regime shift, was insufficient.

The state of the red mullet population in the centralsouthern Tyrrhenian Sea has also been evaluated in previous studies (Anonymous 2002; Tserpes et al. 2002; Spedicato et al. 2006). These recommended, as in other Mediterranean areas (Merino et al. 2007), the reduction of fishing pressure and the protection of recruitment, although survey-based indices of abundance did not show any trend, but the data time series 

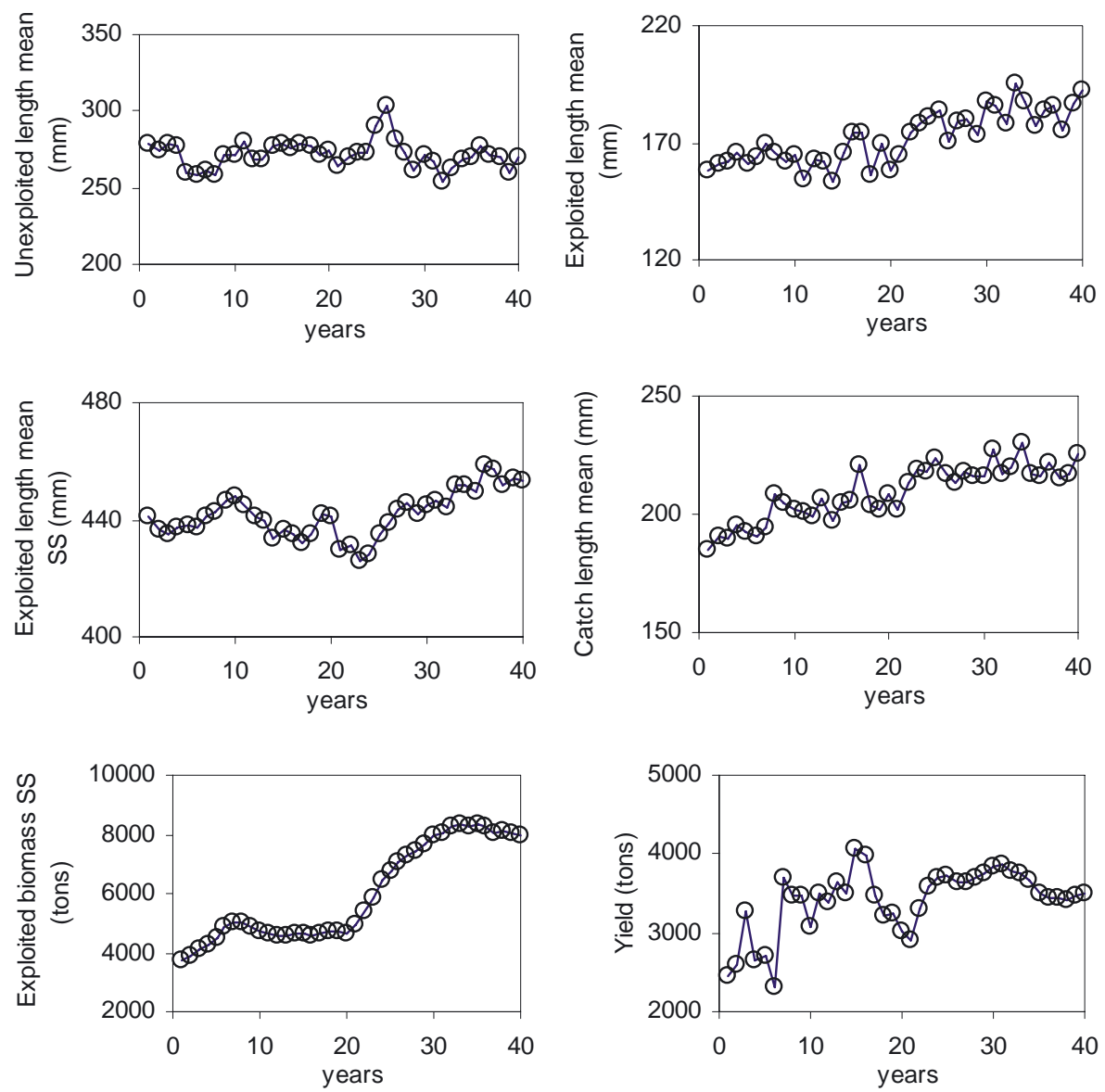

Fig. 5. Simulation results for European hake in the Aegean Sea: mean length in the unexploited population, in the exploited population and in the catch, exploited spawning-stock biomass and yield. Parameter values for the ALADYM simulation model are given in Tables 1a-b and Table 3. Total mortality $Z$ was $\sim 0.9$ for years 1 to 20 and 0.78 thereafter. An increase in mesh size was introduced in year 8 .

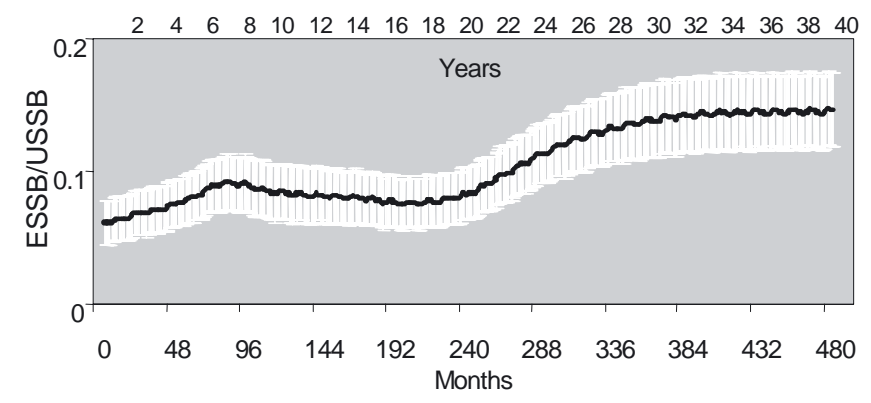

Fig. 6. Month and year variations of the indicator $\operatorname{ESSB} /$ USSB (exploited to unexploited spawning-stock biomass) with relative standard deviations (white strip). Simulation over 40 years (1000 runs) for European hake in the Aegean Sea.

was shorter at the time. The analyses presented in this study corroborate the signs of deterioration in the red mullet population. Thus, the simulation approach supports the usefulness of coupling stock evaluations based on indicators directly estimated from scientific survey data (Petitgas et al. 2007) with those derived from simulation modelling. This integrated approach has the advantage of associating reference levels, which have a probability profile, with model-based indicators. This helps us to work out the possible effects of pressure levels on population metrics in the long-term.

A recovery plan was made for the northern stock of European hake in the Bay of Biscay in 2004, following a previous emergency management plan. Based on recent $S S B$ estimates and fishing mortality (ICES 2006), ICES classified this stock as being at full reproductive capacity and being harvested sustainably. $S S B$ appears to have been very close to $B_{\mathrm{pa}}$ over the last 3 years, and $F$ has been around the precautionary fishing mortality reference point $F_{\text {pa }}$ since 2001. As the growth rate and thus the age determination and productivity of northern hake stocks are uncertain, absolute estimates of $S S B$ and $F$ should be considered with caution. In the "mean $Z$ " scenario explored in the present study ( $Z$ lower and constant except for three years) signs of negative changes were identified following the period of mortality increase. Alternate positive and negative changes also occurred as a consequence of recruitment fluctuations, which became more severe when they coincided with fishing pressure intensification. ALADYM simulation results confirmed the conclusion of the indicator approach (Petitgas et al. 2007), i.e. "Knowing the worrying state of the stock at the beginning of the EVHOE surveys (NE Atlantic Ocean, Celtic Sea and Bay of Biscay surveys) and as no improvement occurred in recent years, on the contrary some 
deteriorations of the indices for older age groups, it seems necessary to reduce fishing mortality". In the case of the "high $Z$ " scenario, a continuous decrease, with some fluctuations, of the $E S S B / U S S B$ metric was observed. The population survived under these high mortality conditions because independence of recruitment from the parental stock was assumed. Thus, based on the simulation results, a sustainable exploitation rate of European hake population would aim at $Z$ values ranging from " $Z$ mean" (1.04) to " $Z$ low" (0.78). One may wonder why the observed catch levels and the simulated catches were rather close. Could this have happened by pure luck? Our understanding is that the European hake recruitment recorded over the eastern continental shelf of the Bay of Biscay during the autumn groundfish survey might supply the hake fishery beyond this area (ICES area VIIIab). This would then imply that part of the fishing mortality $F$ assessed using the ALADYM model might in fact be due to hake migration from VIIIab to neighbouring areas.

The evaluation of composite management options applied to the European hake stock in the Aegean Sea, which is representative of the Mediterranean rules, gives the opportunity to explore long-term effects of management measures on this population. Recommendations from previous studies regarding the state of the hake stock in the Aegean Sea have stressed that there is a situation of overexploitation and the need to reduce fishing pressure (Merino et al. 2007; Tserpes et al. 2007). The analysis conducted in the present study identifies signs of positive changes after 2001, as a consequence of a mesh size increase. Similar conclusions were also reached by Merino et al. (2007). In addition, the reduction of fishing pressure on the Aegean European hake population determines a positive change in the long-term, increasing the current level of the $E S S B / U S S B$ metrics by about $50-60 \%$. There seems to be good agreement between the above results and those obtained from the indicator approach, in particular with the CUSUM analysis (Petitgas et al. 2007), which showed positive changes (mainly in the abundance) after 1998. However, exploitation usually reduces population stability and, in addition, our predictions could be rather optimistic because the hidden mortality of the escaped fish was not considered. Furthermore, the "implementation uncertainty" was not assumed, given the difficulties arising from a "passive management" framework (Lleonart and Maynou 2003; Caddy 2006). Thus, these results should be interpreted more as a trend in the consequences of management options for the population metrics than exact quantitative predictions.

A simulation study evaluating composite management scenarios was also conducted for the eastern stock of cod in the Baltic Sea, in which the consequences of different strategies applied alone or in combination were predicted (Fisboat website: http://www.ifremer.fr/drvecohal/fisboat/). In this case, model-based indicators related to the fishery status quo showed low spawning-stock biomass (SSB), which is the present case with Baltic cod. This indicator only slightly improved after a fishing ban during the spawning season (JulyAugust). Thus, a very drastic measure was simulated, i.e. a 2 -year total fishery ban, as recommended by ICES. The results were the restoration of a safe level of $S S B$ (exceeding $B_{\text {lim }}$ ) and a remarkable increase in fish length, but the beneficial effects vanished in a few years ( $\sim 5$ years) if fishing returned to the previous intensity levels. A continuous reduction in the fishing pressure ( $10 \%$ per year for 10 years), until a stable value $(F=0.3)$ was reached, seemed an effective measure to restore the eastern cod population to safe conditions.

The simulation studies reveal the flexibility of the ALADYM model to be used for different purposes, in particular the assessment of the response of different indicators to pressure, testing the viability of $\mathrm{Z}$ increase in long-term scenarios, and evaluating how complexity in the population model mirrors composite management options.

The current characteristics of the model do not, however, allow environmental or spatial components to be taken into account explicitly (e.g. spatial distribution of population stages; Bartolino et al. 2008). The influence of these components on population dynamics is presently incorporated into life history traits like natural and total mortality, and the stock recruitment relationship. Future developments of ALADYM, introducing new factors into the model, would enable such more complex situations to be handled.

Acknowledgements. This study was partially funded by the European Commission under the Fisboat project (FP5 - 502572) and also partly supported by the Image project (FP6 - 044227).

\section{References}

Abella A.J., Serena F., 1998, Selettività e vulnerabilità del nasello nella pesca a strascico. Biol. Mar. Medit. 5, 496-504.

Anonymous, 2002, Stock Assessment in the Mediterranean SAMED. Final Report EU Project n 99/047.

Anonymous, 2006, National Program for Fisheries Data Collection 2002-2006 (ER 1543/2000). Techn. Rep. HCMR.

Bartolino V., Ottavi A., Colloca F., Ardizzone G.D., Stefansson G., 2008, Bathymetric preferences of juvenile European hake (Merluccius merluccius). ICES J. Mar. Sci. 65, 963-969.

Caddy J.F., 2006, The potential use of indicators, reference points and the traffic light convention for managing Black Sea fisheries. In: Lembo G. (ed.). Selected papers presented at the Workshop on biological reference points. Stud. Rev. GFCM-FAO, No. 83.

Chen S., Watanabe S., 1989, Age dependence of natural mortality coefficient in fish population dynamics. Nippon Suisan Gakkaishi 55, 205-208.

Cooke J.G., 1999, Improvement of fishery-management advice through simulation testing of harvest algorithms. ICES J. Mar. Sci. 56, 797-810.

Cotter J., Petitgas P., Abella A., Apostolaki P., Mesnil B., Politou C.Y., Rivoirard J., Rochet M.-J., Spedicato M. T., Trenkel V.M., Woillez M., 2009a, Towards an ecosystem approach to fisheries management (EAFM) when trawl surveys provide the main source of information. Aquat. Living Resour. 22, 243-254.

Cotter J., Mesnil B., Witthames P., Parker-Humphreys M., 2009b, Notes on nine biological indicators estimable from trawl surveys with an illustrative assessment for North Sea cod. Aquat. Living Resour. 22, 135-153.

de Pontual H., Groison A.L, Piñeiro C., Bertignac M., 2006, Evidence of underestimation of European hake growth in the Bay of Biscay, and its relationship with bias in the agreed method of age estimation. ICES J. Mar. Sci. 63, 1674-1681. 
Fiorentino F., Zamboni A., Relini G., 1998, La selettività della rete a strascico in Merluccius merluccius sulla base delle esperienze riportate in letteratura. Biol. Mar. Medit. 5, 465-474.

Haddon, M., 2001, Modelling and quantitative methods in fisheries. Chapman \& Hall CRC.

Hilborn R., Mangel M., 1997, The ecological detective: confronting models with data. Princeton University Press.

ICES, 1991, Report of the working group on fisheries units in subareas VII and VIII. Int. Council Explor. Sea C.M. 1991/Assess. 24.

ICES, 2006, Report of the working group on the assessment of southern shelf stocks of hake, monk and megrim (WGHMM), 9-18 May 2006, Bilbao. ICES CM 2006/ACFM:29.

Jensen A.L., 1996, Beverton and Holt life history invariants result from optimal trade-off of reproduction and survival. Can. J. Fish. Aquat. Sci. 53, 820-822.

Lembo G., Abella A., Fiorentino F., Martino S., Spedicato M.-T., 2009, ALADYM: an age and length-based single species simulator for exploring alternative management strategies. Aquat. Living Resour. 22, 233-241.

Levi D., Andreoli M.G.,. Bonanno A,. Fiorentino F, Garofalo G., Mazzola S., Norrito G., Patti B., Pernice G., Ragonese S., Giusto G.B., Rizzo P., 2003, Embedding sea surface temperature anomalies into the stock recruitment relationship of red mullet (Mullus barbatus L. 1758) in the Strait of Sicily. Sci. Mar. 67, 259-268.

Lleonart J., Maynou F., 2003, Fish stock assessments in the Mediterranean: state of the art. Sci. Mar. 67, 37-49.

Mace P.M., 1994, Relationships between common biological reference points used as threshold and targets of fisheries management strategies. Can. J. Fish. Aquat. Sc. 51, 110-122.

Mace P.M., Sissenwine M.P., 1993, How much spawning per recruit is enough? In: Smith S.J., Hunt J.J., Revered D. (eds.) Risk evaluation and biological reference points for fisheries management. Can. Spec. Publ. Fish. Aquat. Sci. 120, 101-118.

Martin I., 1991, A preliminary analysis of some biological aspects of hake (Merluccius merluccius L. 1758) in the Bay of Biscay. ICES CM 1991/G:54.

Maunder M.N., Harley S. ,Hampton J., 2006, Including parameter uncertainty in forward projections of computationally intensive statistical population dynamic models. ICES J. Mar. Sci. 63, 969979.

Merino G., Karlou-Riga C., Anastopoulou I., Maynou F., Lleonart J., 2007, Bioeconomic simulation analysis of hake and red mullet fisheries in the Gulf of Saronikos (Greece). Sci. Mar. 71, 525535.

Murua H., Motos L., 2006, Reproductive strategy and spawning activity of the European hake Merluccius merluccius (L.) in the Bay of Biscay. J. Fish Biol. 69, 1288-1303.

Murua H., Lucio P., Santurtún M., Motos L., 2006, Seasonal variation in egg production and batch fecundity of European hake Merluccius merluccius (L.) in the Bay of Biscay. J. Fish Biol. 69, 1304-1316.

NRC, 1998, Improving fish stock assessments. Washington DC, National Academy Press.
Papaconstantinou C., Stergiou K., 1995, Biology and fisheries of eastern Mediterranean hake (M. merluccius). In: Alheit J., Pitcher T.J. (eds.) Hake: Biology, fisheries and markets. Chapman \& Hall, London, pp. 149-180.

Papaconstantinou C., Petrakis G., Caragitsou E., Labropoulou M., Karkani M., Vassilopoulou V., Mytilineou Ch., Lefkaditou E., Siapatis A., Kavadas S., Chatzinikolaou P., Anastassopoulou A., Kapiris K., Terrats A., Dogrammatzi A., Bekas P., Christidis G., Fourtouni A., 1998, Development of the Greek fisheries. Assessment of the demersal fisheries resources of commercial interest in the S. Aegean Sea. Techn. Rep. NCMR.

Petitgas P., Poulard J.-C., Radtke K., Spedicato M.-T., Ibaibarriaga L., Politou C.-Y., Korsbrekke K., Deernberg C., Fernandes P., 2007, Comprehensive indicator-based diagnostics of fish stocks using fishery-independent survey data: the FISBOAT Rep. ICES CM 2007/O.

Punt A.E., 2003, Managing West Coast groundfish resources through simulations. Fish. Bull. 101, 860-873.

Rochet M.-J., Rice, J.C., 2009, Simulation-based management strategy evaluation: ignorance disguised as mathematics? ICES J. Mar. Sci. 66, 754-762.

Rochet M.-J., Trenkel V.M., 2009, Why and how could indicators be used in an Ecosystem Approach to Fisheries Management? In: Beamish R.J., Rothschild B.J. (eds.), The future of fisheries science in North America, Fish \& Fisheries Series, Springer, pp. 209-226.

Sparre P., Venema S.C., 1998, Introduction to tropical fish stock assessment. Part 1, manual. FAO Fish. Techn. Pap. 306 Rev. 2.

Spedicato M.T., Carbonara P., Rinelli P., Silecchia T., Lembo G., 2006, Biological reference points based on spawning stock biomass levels: the case of red mullet (Mullus barbatus L., 1758). Biol. Mar. Medit. 13, 112-123.

Tserpes G., Fiorentino F., Levi D., Cau A., Murenu M., Zamboni A., Papaconstantinou C., 2002, Distribution of Mullus barbatus and M. surmuletus (Osteichthyes: Perciformes) in the Mediterranean continental shelf: implications for management. In: Abelló P., Bertrand J.A., Gil de Sola L., Papaconstantinou C., Relini G., Souplet A. (eds.) Mediterranean marine demersal resources: the MEDITS International Trawl Survey (1994-1999). Sci. Mar. 66 (Suppl. 2) 39-54.

Tserpes G., Haralabous J., Maravelias C., 2007, A non-equilibrium surplus production model approach using Medits data. GFCMSAC-Sub-Committee Stock Assessment. Workshop on trawl survey based monitoring fishery system in the Mediterranean, Rome 26-28 March 2007.

Thompson W.F., Bell F.H., 1934, Biological statistics of the Pacific halibut fishery. 2. Effect of changes in intensity upon total yield and yield per unit of gear. Rep. Int. Fish. (Pacific Halibut) Comm. 8.

Wang S.P., Maunder M.N., Aires-da-Silva A., 2009, Implications of model and data assumptions: An illustration including data for the Taiwanese long-line fishery into the eastern Pacific Ocean bigeye tuna (Thunnus obesus) stock assessment. Fish. Res. 97, 118-126. 